\title{
Research on Educational Curriculum Reform of Medical Nursing in Higher Vocational School
}

\author{
ZHU You- ping ${ }^{1, a}$ \\ ${ }^{1}$ Continuing Education College, Ezhou Vocational University, Ezhou, Hubei China 436000 \\ aZYP_199@163.com
}

Key words: medical nursing, curriculum reform, higher vocational school

\begin{abstract}
The medical nursing teaching is the most universal and abnormal subjects in the medical higher vocational school. The educational curriculum and the relative reforms were researched to improve the teaching level. Traditionally, the medical nursing education was not adaptive to the development of medicine, the educational objective was not enough clear, and the teaching course was deviated to the real social demands. The practice and training equipments were relative lagged to the requirements, and the level of teachers was not satisfying. According to the sharp problems, the solutions were researched and the corresponding suggestions were presented. As the important status of nursing subject in the medicine major, the mode of medical nursing was changing from traditional function nursing to the whole mind and body nursing. The courses of nursing educational also were needed to changing with the same pace. The reform should be put out for the progress of medical nursing. Four aspects were analyzed such as target and level location, optimization of the courses system, enhancement of the training construction and improvement of the teacher's level. Research results show that the suggestions proposed in this paper is meaningful and it has prospective application value in the medical nursing educational reform.
\end{abstract}

\section{Introduction}

With the development of the society and civilization, the medical mode is changing basically, the initial medical mode is sole biomedicine mode, and it becomes the psychology and biomedicine mode. Nowadays, id is developed as the society- psychology - biomedicine mode. And yet at the same time, the medical nursing mode is changing with the corresponding pace, it is changed from traditional function nursing to the mind - body overall nursing. But the medical nursing teaching is still staying the traditional function nursing mode, and it cannot adapt to the development of the real requirements ${ }^{[1]}$.

According to the statistics, the nursing personnel requirement is above 300 million in the world. According to the Ministry of Health Statistics in China, the nursing personnel are about 138.6 million, and it is about $30.26 \%$ by the whole medical personnel. There is still great distance to the standard of WTO. The ratio of nurses to the beds is about $0.33: 1$ in average, and it hasn't reached to the norm as $0.4: 1$. According to the prediction and program that the ratio of doctors to nurses need to reach 1:2 in 2015, the society needs each levels of nurses about 150, 000 per year in China. Both of the quality and quantity are lacking, for meeting and making up the insufficiency, the basic nursing education needs to be reformed. The teaching resources need to be readjusted. If the phenomenon of insufficiency is continue or increasing, the medical nursing will confront great challenge in future. For the realization of mode transformation, the medical nursing education mode reform is necessary. The traditional and dated concepts need to be updated ${ }^{[2]}$. Combining with the diseases, nursing program and healthy teaching, the new nursing concept and mode should be applied in the clinical nursing practice. The sole traditional disease nursing is replaced finally ${ }^{[3-5]}$.

Generally speaking, there are about 3 aspects of problems in traditional medical nursing education mode. Firstly, the teaching concept is lag. Concept determines the behavior, if the new education is guided by the dated concept, the education cannot be developed well. Secondly, the teaching books are lag, in the dated teaching books mechanism, the special science is empathized, but the civilization and humanities of nursing subjects are neglected, so the old teaching books cannot adapted to the new nursing concept. Thirdly, the educational objective is fuzzy. In order to improve the teaching quality of medical nursing wholly, the teaching and training situations of 
nursing courses in Higher Vocational School are investigated and researched. On the basis of the current problems and difficulties, the adaptable teaching system is probed. And the scientific, exercisable suggestions are proposed. It provides good and meaningful reference in the reform of medical nursing education.

\section{Existing problems of medical nursing education}

Because the internal medicine plays most important in the whole medicine system, and the internal medical nursing is the most important subject in the nursing education system. The internal medicine nursing education is researched firstly, and the existing problems are presented as follows. A. Objective and position of nursing education is ambiguous

Currently, for the Higher Vocational School education, the medical nursing objective is fuzzy and ambiguous, the location and position is not accurate, the phenomenon of being unfit for a higher post but unwilling to take a lower one is existing, it shows as two inclinations as: Firstly, the nursing curriculum is just compression of the undergraduate medical curriculum. The cultivation of nursing talent is due to the academic talents training mode. And it leads to the low ability in occupation. Secondly, on the other side, the curriculum may just enlarge the middle nursing curriculum, just pay attention to the skill teaching, and ignore the cultivation of quality. The extreme phenomena cannot adapt the development of society and the development of medicine scientist.

\section{B. Curriculum system deviate the essence of nursing}

Firstly, the curriculum lacks the characteristics of the nursing profession in Higher Vocational School. It is shown as follows: the curriculum system is come from the undergraduate education pattern. For example, the public courses are too many and too deep, too difficult, the application property is lacking. On the other hand, the basic medical knowledge is too tiny and too many with trifles, it emphasizes the subjects knowledge too much. Clinical course is too biased to the nursing theory but ignored the nursing practice. Additionally, the classifications of curriculums are too many, overcome the principle of basic necessary requirement. And yet, it just use the middle medical curriculum, and the nursing humanities courses are inadequate, then lead to the lacking of occupation quality and adaptive faculty in occupation.

Secondly, subject characteristics of theory teaching are not obvious. In the effects of the biomedicine mode, the theory teaching mainly takes the patient nursing as the center, and teaching the pathological mechanism, clinical manifestation, treatment principle and disease nursing, which just like cultivating medical students.

Thirdly, the training practice characteristic is not strong and enough, the practice is arranged in the last year for the medical and nursing students, the interval of theory teaching and practice is too long, so the skill and knowledge have not obtained the effective enforcement. Some knowledge need to be studied renew in the practice.

For the practice, the comprehensive evaluating indicator is absent, and the practice identification cannot reflect the fact. As for the evaluation of the practice conclusion, it is lack of efficient and effective evaluating indicator and method, perhaps the practice report is the ultimate evaluating index. But the report cannot reflect the real practical ability and technical level of the students. This conclusion and evaluating method certainly can setback the enthusiasm of the students.

\section{Conditions and facilities are old and cannot meet the requirements}

Fourthly, the hardware facilities and teaching material and teaching books are lagging 1 behind in clinical practice. Some colleges and universities invest little in the practice factories, practice environment, practice and experiment platforms. The high-tech equipments are lack. The hardware facilities are old. Eventually, it results that the practice subject becomes a mere formality, and the students involve the practice just like for tea and biscuits. The experiment education and the practice education are implemented for decades just as one day, year after year, day after day, and there is no improvement, no development. Limited to the old teaching system, the new and developed knowledge cannot be presented in the class. It cannot show the predominant and effective performance of modern educational technology.

D. Quality and quantity of teachers are low and inadequate

According to the recruitments of some higher vocational medical schools, it emphasizes the higher education 
too much, but for some high educated teachers, and they always come from the educated universities to the working schools, the practice and experience are not enough, the practice skill is low. With the increasing and enlarging of students, but the teachers are not enlarged for saving the cost and resources, so the quality and quantity of high talent teacher are inadequate and lacking.

\section{Solutions and reform suggestions of improving the nursing education quality}

According to the harsh problems as above, the education reform should be implemented immediately, some effective suggestions are proposed for improving the quality of nursing teaching and nursing education based on the concept transformation and curriculum adjustment, the purpose is just heighten the nursing education in higher vocational medical schools to a great level.

A. Accurate location of objective and teaching level

The objective of nursing education in higher vocational medical schools is cultivation of high skilling and specialty talent. We should insist the focus of improving of course quality, purpose of service and guide of obtaining jobs and look for a development mode combining production, teaching and research to innovatively change the teaching methods of the medical nursing major.

B. Optimizing the curriculum system

(1) Curriculum setting and content of courses. According to the characteristics of medical nursing and nursing occupation, the requirements of knowledge, ability and quality of nursing personnel in clinic are analyzed in detail. The curriculum system program is completed. The teaching contents are readjusted and reformed, and the relative contents which have close correlation to the medical nursing are selected. The unconcerned contents to the medical nursing should be neglected and ignored, and the nursing characteristics should be outstanding. The courses ratio of each module should be reasonable in the meanwhile. Though study and training, the basic theory is enhanced, and the skill application ability is improved, the knowledge is broadened. The interaction of knowledge to the occupation can be connected perfectly.

(2) Selection of good teaching books. According to the lag of nursing books and facilities, the advanced and professional books should be selected as the teaching books. Also the lectures, teaching notes and courseware should be updated immediately. The lectures should make the nursing program as the structure, the overall nursing concept and learning method and the clinic comprehensive ability can be cultivated in the advanced curriculum system.

(3) Practice teaching. For the arrangement of teaching practice, the clinical practice needs to be stated with the course learning. The "clinic -class - clinic" teaching process is constructed, and makes the students enlarge the knowledge from class to the clinic, enlarge the theory to the practice, then the weakness of teaching in the classroom is made up, the distance between the theory to the clinic is reduced. According to the teaching method, the CAI course ware, the audiovisuals, simulated teaching tools etc. should be taken in advantage. Qualified college students should have basic moral, intellectual, physical and aesthetic quality. Especially for the medical nursing professional training process, while strengthening the professional knowledge learning, the schools should add humanistic elective courses to teaching plan, pay much attention to students' mental and physical health, only by this way, the students will pay attention to the metal and physical health oh patients in the occupation.

(4) Evaluation mechanism. In the evaluation and examination process, the evaluation method can taken several forms such as written examination, interview, case discussion, reading report and clinical ability test etc. the examination halls can be arranged in the classroom, laboratory, bed-ward etc. and the evaluation and exam should pay much more attention to the practice skill and clinical ability for promoting students to improve the ability which solving the real practical problem in clinic.

C. Adjustment of the practice time in clinic.

Of course, the performance and result of practice is due to the cost time and striving degree. At present, in China's higher education system, the major which has practice time medical majors, all these majors related to the medical professional have one year's practice time no matter the college education, general secondary education or the undergraduate education.. According to this 
mechanism, it reflects that the practice is important in improving the ability in profession. But the practice time is very less as presented and analyzed as above, it is necessary to increase the practice time to a certain degree reasonably, but the whole study time in the university is limited, confronted to the so many subjects and how to coordinate the contradiction between the practice time and theory study time is a hard problem which need to be researched. The application students should put much attention to the practice and training exercise with reduction of some irrelevant curriculum learning, and it should be put more practice time for this type of students, In conclusion, how to coordinate the contradiction between theory study and the practice exercise, and find the best balance of the learning and practice, the problem should be solved by the effort of the relevant department. And the ultimate objective is for the development of the social, development of the science with cultivation of the useful talents.

\section{Conclusions}

The educational curriculum and the relative reforms were researched to improve the teaching level. The practice and training equipments were relative lagged behind the requirements, and the level of teachers was not satisfying. According to the sharp problems, the solutions were researched and the corresponding suggestions were presented. As the important status of nursing subject in the medicine major, the mode of medical nursing was changing from traditional function nursing to the whole mind and body nursing. The courses of nursing educational also were needed to changing with the same pace. The reform should be put out for the progress of medical nursing. Four aspects were analyzed such as target and level location, optimization of the courses system, enhancement of the training construction and improvement of the teacher's level. Research result shows that the suggestions proposed in this paper is meaningful and have good value in the teaching and clinical practice.

\section{References}

[1] Chen Chaowen. Discussions on the Reform of Tanching Practice for Computer Science Majors[J]. Journal of Nanning Teachers College, 2005, 22(3):75-77.

[2] DENG Jing-sheng. The new view about reform of the method of pre-service teacher education practice under the background of new curriculum[J]. CAREER HORIZON, 2012, 8(9): 81-83.

[3] Hulman LS.. Knowledge and Teaching: Foundations of the New Reform[J]. Harvard Educational Review, 1987, 57 (1): 135-143.

[4] LIU Xu-dong. On Educational Practice Ability of Normal Students and the Reform of Education and Internship Program[J]. Contemporary Education and Culture, 2011, 3(2): 74-79.

[5] Kato, Takao. The End of Lifetime Employment in Japan: Evidence from National Surveys and Field Research [J]. Journal of the Japanese and International Economies, 2001, 4: 489-514. 